\title{
Phytochemical Indicaxanthin Inhibits Colon Cancer Cell Growth and Affects the DNA Methylation Status by Influencing Epigenetically Modifying Enzyme Expression and Activity
}

\author{
Flores Naselli ${ }^{a}$ Nigel Junior Belshaw ${ }^{b} \quad$ Carla Gentile ${ }^{a} \quad$ Marco Tutone ${ }^{a}$ \\ Luisa Tesorier $^{a}$ MariaAntonietta Livrea ${ }^{a}$ Fabio Caradonna ${ }^{a}$ \\ aDipartimento di Scienze e Tecnologie Biologiche Chimiche e Farmaceutiche (STEBICEF), \\ Universit à di Palermo, Palermo, It aly; 'b Instit ut e of Food Research, Norwich, UK
}

\author{
Key Words \\ Colorectal cancer - Chemoprevention - Phytochemicals - Indicaxanthin - Epigenetics . \\ DNA methyltransferase $\cdot$ Molecular modeling $\cdot$ Betalains
}

\begin{abstract}
Background: Recently, we have shown anti-proliferative and pro-apoptotic effects of indicaxanthin associated with epigenetic modulation of the onco-suppressor $p 16^{I N K 4 a}$ in the human colon cancer cell line $\mathrm{CACO}$. In the present study, the epigenetic activity of indicaxanthin and the mech an isms involved were further investigated in other colorectal cancer cell lines. Methods: LOVO1, CACO2, HT29, HCT116, and DLD1 cells were used to evaluate the potential influence of consistent dietary concentrations of indicaxanthin on DNA methylation, and the epigenetic mechanisms involved were researched. Results: Indicaxanthin exhibited anti-proliferative activity in all cell lines but $\mathrm{HT} 29$, induced demethylation in the promoters of some methylation-silenced onco-suppressor genes involved in colorectal carcinogenesis ( $16^{I N K A a}$, GATA4, and ESR1), and left unchanged others which were basally hypemethylated (SFRP1 and HPP1). In apparent contrast, cell exposure to indicaxanthin increased DNMT gene expression, although indicaxanthin appeared to be an inhibitor of DNMT activity. Indicaxanthin also increased the expression of genes involved in DNA demethylation. Finally, an in silico molecular modelling approach suggested stable binding of indicax anthin at the DNMT1 catalytic site. Conclusions: Our findings contribute to new knowledge in the field of phytochemicals and specifically suggest dietary indicaxanthin as a potential epigenetic agent to protect colon cells against tumoral alterations.

O 2015 S. Karger AG, Basel
\end{abstract}

